\title{
Medical students' attitudes towards psychiatry improve following psychiatry clinical placements: the ATPP study
}

Authors:

Emanuele F Osimo ${ }^{1,2,3, *,+}$, Lydia Mariner ${ }^{2,+}$, Paul O Wilkinson ${ }^{1,2}$

1. Department of Psychiatry, School of Clinical Medicine, University of Cambridge, Cambridge, UK

2. Cambridgeshire and Peterborough NHS Foundation Trust, Cambridge, UK

3. MRC London Institute of Medical Sciences, Institute of Clinical Sciences, Imperial College, Hammersmith Campus, London, UK

${ }^{+}$contributed equally to this work

* Address for Correspondence: Dr Emanuele F. Osimo, Department of Psychiatry, University of Cambridge, Herchel Smith Building, Cambridge Biomedical Campus, Cambridge CB2 0SZ, UK.

Tel: +44 7454 647024; E-mail: efo22@cam.ac.uk 


\section{Abstract: \\ Purpose}

In previous research, personality and exposure to psychiatry were independently shown to shape medical students attitudes towards psychiatry (ATP). This study investigated the role of psychiatry placements and personality types on medical student attitudes towards psychiatry (ATP).

\section{Design/methodology/approach}

All medical students from four consecutive years at Cambridge University, UK were invited to take part in an online questionnaire including the ATP-30 Questionnaire and The Big Five Factor personality Inventory (BFI).

\section{Findings}

Students who had completed their psychiatry placement had more positive ATP than students who had not $(\mathrm{t}=-3.24$, adjusted $\mathrm{p}=0.004)$. However, this was not reflected in an increased self-reported likelihood of choosing psychiatry as a career $(\mathrm{t}=0.28$, adjusted $\mathrm{p}=0.78)$. Higher agreeable personality scores were associated with both a higher willingness to take up psychiatry as a career (linear model estimate $0.06 ; \mathrm{p}=0.03$ ), and more positive ATP (linear model estimate $0.14 ; \mathrm{p}<0.0001$ ).

\section{Originality}

This work seems to confirm that exposure to psychiatry improves attitudes towards psychiatry. Agreeable personality traits were also associated with a higher willingness to take up psychiatry postgraduate training. These findings might help shape future campaigns to improve the profile of psychiatry training. Future research on this topic is needed to address whether improved ATP among medical students can longitudinally improve recruitment into post-graduate psychiatry training.

\section{Key words}

Attitudes towards psychiatry; personality; recruitment; placements; questionnaire 


\section{Introduction:}

Recruitment and retention of doctors into psychiatry training has been challenging in the United Kingdom (Mukherjee et al., 2013). According to the 2019 workforce census the rate of unfilled NHS consultant psychiatrist posts in England has doubled in the last six years. One in 10 posts are vacant (9.9\%) - up from one in 20 in 2013 (Royal College of Psychiatrists, 2019c). Nationally, trainee numbers have, until recently, been falling, and $40 \%$ of trainees do not proceed directly from core to higher training (Royal College of Psychiatrists, 2019a). The Royal College of Psychiatrists have launched a workforce to investigate the reasons for this (Royal College of Psychiatrists, 2019a). The 2017 "Choose Psychiatry" campaign, aiming to improve the numbers of medical students and foundation doctors considering psychiatry as a career, has been successful in boosting psychiatry junior doctor posts fill rates (Royal College of Psychiatrists, 2019b), however there is more work to be done, and these improvements need to be sustained.

There has been considerable interest around the factors that shape students' attitudes towards psychiatry as a tool to improving retention and recruitment into this specialty internationally. A systematic review in 2013 showed that 74 medical schools have been surveyed in 22 different countries found that although there is a mix of attitudes, overall attitudes tend to be positive, but psychiatry as a career choice remained unpopular (Lyons, 2013).

Research into the role of psychiatric teaching and rotations on medical students' perceptions found that attending formal teaching led to the development of more favourable attitudes towards psychiatry (Niedermier et al., 2006). In the US, Kuhnigk et al took this one step further and found that positive educational and personal experience increased positive attitudes (Kuhnigk et al., 2007). McParland et al. studied UK medical students' attitudes towards psychiatry at a London Medical School in relation to their clinical attachment, and considered how this impacted their career choices (McParland et al., 2003). They found that improvements in attitudes were dependent on the clinical 
teacher, and for students whose attitudes improved, the likelihood of choosing psychiatry as a career increased (McParland et al., 2003). However, this study did not take into account personality types. Further, a recent study of 1,356 German speaking medical students in four different European countries showed that female gender and previous experience were associated with more interest in psychiatry as a career choice (Warnke et al., 2018). This study indicated that further research into personality factors is warranted to further understand how personality impacts on attitudes and career choice.

Previous research investigated the role of personality types using the Myers-Briggs indicator, and found that doctors with "intuitive" and "introvert" traits were more likely to choose psychiatry (McCaulley, 1977, Stilwell et al., 2000).

The Five Factor Model of personality (FFM) is a well-established framework which examines normal adult personality traits (McCrae and John, 1992, McCrae and Costa Jr, 2008). Lievens et al. found the FFM to be a uniform, comprehensive and robust framework for describing medical students' personality characteristics (Lievens et al., 2002). They also found that higher scores for extraversion and agreeableness, two dimensions defining the interpersonal dynamic, may be beneficial for doctors' collaboration and communication skills in future professional practice. High scores in conscientiousness predicted better outcome in examinations. Additional traits concerning sociability (i.e. extraversion, openness, self-esteem and neuroticism) have also been identified as relevant, particularly in the applied medical environment. In a Finnish study, higher openness and lower conscientiousness were associated with specializing in psychiatry (Mullola et al., 2018). This backed up an earlier study which found high levels of openness attracted medical students in Australia to psychiatry (Malhi et al., 2011). 
In summary, previous studies either investigated the effect of personality traits on attitudes towards psychiatry, or investigated associations between the role of psychiatric teaching and rotations and likelihood and attitudes towards psychiatry. An up-to-date study which considers both students' personality types and exposure to psychiatric rotations in shaping attitudes towards psychiatry, as well as and how this may influence recruitment to and retention in the speciality was therefore needed.

Therefore, our study aimed to test a) whether medical students had different attitudes towards psychiatry, and a career in psychiatry, before and after a psychiatric placement; and b) the associations between personality and attitudes towards psychiatry in medical students. Given previous evidence we expected students high in openness traits to be more favourable towards psychiatry, with medical students overall being high in conscientiousness and extraversion. 


\section{Methods}

\section{Participants}

Most students on the Cambridge University medical course study for six years, the latter three of which are clinically-focused. Most psychiatry teaching takes place in year 5. In January in 2018 and 2019, all year 4 and year 6 medical students enrolled at Cambridge University were invited to take part in the online survey via email. The main psychiatry placement takes place in year 5, thus we aimed for half of students to have already had a psychiatry placement. Written informed consent was obtained from all participants. All data was collected anonymously. The study was approved by the University of Cambridge Psychology Research Ethics Committee (ref HVS/2017/2173).

\section{Scales and questionnaires}

Students were asked about:

- Age group (<20, 20-25, 25-30, $>30$ years) and gender (male, female, other/prefer not to say)

- How likely they were to choose psychiatry as a career on a continuous scale from 0 to 100

- Which speciality they were most attracted to as a potential career.

Students were also administered:

Attitudes towards Psychiatry Questionnaire (ATP-30): The ATP-30 has been frequently used to measure medical students' attitudes toward psychiatry (Warnke et al., 2018, Strebel et al., 2000, Kuhnigk et al., 2007, Zwerenz et al., 2007) and has proven validity and reliability (Burra et al., 1982). It comprises 30 Likert-scale items, scored between 1 , strongly agree and 5 , strongly disagree. The questionnaire includes a diverse set of statements related to mental illness and psychiatric patients, psychiatric treatments and institutions, psychiatrists, education, knowledge, and psychiatry as a career. The sum score ranges between 30 and 150 points, with high score representing positive attitudes. 
The Big Five Factor Inventory (BFI). The 44 item BFI (John and Srivastava, 1999) was used to measure the following 'big five' (Goldberg, 1990) personality traits: Neuroticism, Extraversion, Openness, Agreeableness and Conscientiousness. Extraversion and Neuroticism scores range between 8 and 40; Agreeableness and Conscientiousness scores range between 9 and 45; Openness scores range between 10 and 50 .

\section{Data collection}

Study data were collected and managed using REDCap electronic data capture tools hosted at the University of Cambridge (Harris et al., 2009). REDCap (Research Electronic Data Capture) is a secure, web-based application designed to support data capture for research studies, providing 1) an intuitive interface for validated data entry; 2) audit trails for tracking data manipulation and export procedures; 3) automated export procedures for seamless data downloads to common statistical packages; and 4) procedures for importing data from external sources.

\section{Statistical analysis}

For categorical vs categorical tests, $\chi^{2}$ was used. To compare groups on normally distributed continuous variables, t-tests (for 2 groups) or ANOVA (for multiple group comparisons) were used. To compare groups on non-normally distributed continuous variables, Wilcoxon rank sum tests (for 2 groups) or Kruskal-Wallis $\chi^{2}$ tests (for multiple group comparisons) were used.

Generalised linear models were used to measure associations between continuous personality scores and both ATP-30 scores and self-described likelihood to take up psychiatry as a career. 
$P$-values were adjusted using the Benjamini \& Hochberg method. The false-discovery rate $(\mathrm{q})$ was set to 0.05 , and results were considered significant when corrected $P$-values were $<0.05$. All statistical analyses were performed in R (R Core Team, 2020). Plots were made using ggplot2 (Wickham, 2009), using the Cairo R graphics device (Urbanek and Horner, 2005). 


\section{Results}

160 students participated in the study, 76 (17.5\% of 434 invited) in 2018 and 84 (19.3\% of 436 invited) in 2019. $95(59 \%)$ were $4^{\text {th }}$ year students and $65(41 \%) 6^{\text {th }}$ year. $94(59 \%)$ participants were female. $11(6.9 \%)$ students saw psychiatry as their preferred future speciality (Table 1$)$.

There were no differences in age, sex, sex by year, year of study, specialism preference, ATP30 score or likelihood to choose psychiatry between the 2018 and 2019 cohorts.

\section{-- TABLE 1 -}

\section{Attitudes towards psychiatry following exposure to psychiatry teaching}

Year 6 students had a significantly more positive attitude towards psychiatry than year 4 students $(t=$ -3.24, adjusted $\mathrm{p}=0.004$; see table 2). However, there was no difference in likelihood of choosing psychiatry between students in year 4 and $6(t=0.28$, adjusted $\mathrm{p}=0.78)$. There were no gender differences in likelihood of choosing psychiatry or attitudes towards psychiatry (adjusted ps all > $0.34)$.

\section{-- TABLE 2 --}

Personality types among medical students interested in psychiatry

Table 3 shows that among different personality trait scores, higher agreeableness was associated with a higher likelihood to take up psychiatry $(0-100)$ (adjusted $p=0.03)$; agreeableness also associated with a more positive perception of psychiatry (as measured by ATP30 scores; adjusted $\mathrm{p}<0.001$ ). 
Table 1: characteristics of the sample

\begin{tabular}{|c|c|c|c|c|c|c|}
\hline & & $\begin{array}{l}\text { cohort } 2018 \\
N=76\end{array}$ & $\begin{array}{l}\text { cohort } 2019 \\
\mathrm{~N}=84\end{array}$ & $\begin{array}{l}\text { overall } \\
N=160\end{array}$ & \begin{tabular}{|l} 
Difference \\
within \\
overall \\
group \\
\end{tabular} & $\begin{array}{l}\text { Cohort } \\
\text { difference } \\
\text { 2018-2019 }\end{array}$ \\
\hline \multirow[t]{2}{*}{ Age group: } & $20-25$ & $73(96.1 \%)$ & $78(92.9 \%)$ & $151(94.4 \%)$ & & \multirow{2}{*}{$\begin{array}{l}\chi^{2}=0.77, \text { d.f. } \\
=1, p=0.38\end{array}$} \\
\hline & $>25$ & $3(3.9 \%)$ & $6(7.1 \%)$ & $9(5.6 \%)$ & & \\
\hline Female sex: & Female & $48(63.2 \%)$ & $46(54.8 \%)$ & $94(58.8 \%)$ & & $\begin{array}{l}\chi^{2}=2.5, \text { df. }= \\
2, p=0.29\end{array}$ \\
\hline Female sex by year: & in year $6^{\text {th }}$ & $20(71.4 \%)$ & $21(56.8 \%)$ & $43(63.2 \%)$ & \multirow{3}{*}{$\begin{array}{l}\chi^{2}=2.7, \mathrm{df} . \\
=2, \mathrm{p}=0.26\end{array}$} & \\
\hline \multirow{2}{*}{$\begin{array}{l}\text { Participants by year } \\
\text { of study: }\end{array}$} & $4^{\text {th }}$ & $47(61.8 \%)$ & $48(57.1 \%)$ & $95(59.4 \%)$ & & \multirow{2}{*}{$\begin{array}{l}\chi^{2}=0.37, \text { df. }= \\
1, p=0.55\end{array}$} \\
\hline & $6^{\text {th }}$ & $29(38.2 \%)$ & $36(42.9 \%)$ & $65(40.6 \%)$ & & \\
\hline \multirow{3}{*}{$\begin{array}{l}\text { What is the } \\
\text { specialism that } \\
\text { attracts you the most } \\
\text { at present? }\end{array}$} & Psychiatry & $7(9.5 \%)$ & $4(4.7 \%)$ & $11(6.9 \%)$ & & \multirow{3}{*}{$\begin{array}{l}\chi^{2}=2.2, \text { df. }= \\
4, p=0.70\end{array}$} \\
\hline & Surgical specialty & $15(20.3 \%)$ & $21(24.7 \%)$ & $37(23.1 \%)$ & & \\
\hline & Medical specialty & $31(41.9 \%)$ & $39(45.9 \%)$ & $70(43.8 \%)$ & & \\
\hline \multicolumn{2}{|c|}{$\begin{array}{l}\text { How likely do you think it is that you will } \\
\text { choose psychiatry as a career? }\end{array}$} & $25.95(23.47)$ & $24.74(22.8)$ & $25.31(23.05)$ & & $\begin{array}{l}\mathrm{t}=0.33, \mathrm{df}= \\
155.4, \mathrm{p}=0.74\end{array}$ \\
\hline
\end{tabular}


Table 2: quantitative results - attitudes towards psychiatry in our sample

\begin{tabular}{|c|c|c|c|}
\hline & & & Contrast \\
\hline & Overall mean (SD) & Females mean (SD) & $\begin{array}{l}\text { t-test; degrees of freedom; } p \\
\text { value (BH-adjusted) }\end{array}$ \\
\hline $\begin{array}{l}\text { How likely do you think it is } \\
\text { that you will choose psychiatry } \\
\text { as a career? whole sample } \\
(\mathrm{N}=160)\end{array}$ & $25.31(23.05) ; \min 0, \max 100$. & $25.96(21.29)$ & $\begin{array}{l}\text { Males vs females: } \mathrm{t}=-0.31, \mathrm{df} \\
=121.7, \mathrm{p}=0.78\end{array}$ \\
\hline $\begin{array}{l}\text { How likely do you think it is } \\
\text { that you will choose psychiatry } \\
\text { as a career? students in year } 4^{\text {th }} \\
(\mathrm{N}=95)\end{array}$ & $25.88(23.29)$ & $25.68(21.73)$ & \multirow{2}{*}{$\begin{array}{l}\text { Year } 4^{\text {th }} \text { vs } 6^{\text {th }}: t=0.28, d f= \\
137, p=0.78\end{array}$} \\
\hline $\begin{array}{l}\text { How likely do you think it is } \\
\text { that you will choose psychiatry } \\
\text { as a career? students in year } 6^{\text {th }} \\
(\mathrm{N}=65)\end{array}$ & $24.48(22.86)$ & $26.32(20.96)$ & \\
\hline $\begin{array}{l}\text { ATP score (a higher score on } \\
\text { the scale indicates a more } \\
\text { positive attitude toward } \\
\text { psychiatry), whole sample } \\
(\mathrm{N}=160)\end{array}$ & 88.89 (15.4); $\min 37, \max 118$ & $90.21(14.63)$ & $\begin{array}{l}\text { Males vs females: } \mathrm{t}=-1.38, \mathrm{df} \\
=127.67, \mathrm{p}=0.34\end{array}$ \\
\hline $\begin{array}{l}\text { ATP score: students in year } 4^{\text {th }} \\
(\mathrm{N}=95)\end{array}$ & $85.72(15.88)$ & $86.6(15.18)$ & \multirow{2}{*}{$\begin{array}{l}\text { Year } 4^{\text {th }} \text { vs } 6^{\text {th }}: t=-3.24, d f= \\
148.49, p=0.004\end{array}$} \\
\hline $\begin{array}{l}\text { ATP score: students in year } 6^{\text {th }} \\
(\mathrm{N}=65)\end{array}$ & $93.52(13.5)$ & $94.88(12.6)$ & \\
\hline
\end{tabular}


Table 3: Associations between personality trait scores, willingness to take up psychiatry as a career and attitudes towards psychiatry scores

\begin{tabular}{|l|l|l|}
\hline & $\begin{array}{l}\text { linear model: personality trait } \sim \\
\text { likelihood of psychiatry } \\
\text { estimate; BH-adjusted } \mathrm{p}\end{array}$ & $\begin{array}{l}\text { linear model: personality trait } \sim \text { atp30 score } \\
\text { estimate; } \mathrm{BH}-\text { adjusted } \mathrm{p}\end{array}$ \\
\hline Personality type: extroversion & $-0.03 ; \mathrm{p}=0.36$ & $0.06 ; \mathrm{p}=0.14$ \\
\hline Personality type: agreeableness & $0.06 ; \mathrm{p}=0.03$ & $0.14 ; \mathrm{p}<0.0001$ \\
\hline $\begin{array}{l}\text { Personality type: } \\
\text { conscientiousness }\end{array}$ & $-0.004 ; \mathrm{p}=0.88$ & $0.08 ; \mathrm{p}=0.07$ \\
\hline Personality type: neuroticism & $0.04 ; \mathrm{p}=0.30$ & $-0.01 ; \mathrm{p}=0.83$ \\
\hline Personality type: openness & $0.03 ; \mathrm{p}=0.37$ & $0.07 ; \mathrm{p}=0.07$ \\
\hline
\end{tabular}




\section{Discussion}

In a sample of four consecutive years of Cambridge medical students $\left(4^{\text {th }}\right.$ and $6^{\text {th }}$ year students from both the 2017-18 and 2018-19 academic years), we set out to test attitudes towards psychiatry, as a speciality and future career, in students who had and had not completed their main psychiatry placements (in year 5). We considered whether personality traits were associated with attitudes towards psychiatry. We found that students who had completed their psychiatry placement had more positive attitudes towards psychiatry than students who had not. However, this was not reflected in an increased self-reported likelihood of choosing psychiatry as a career.

The finding that psychiatry placements improve attitudes towards psychiatry replicates previous similar findings. Stigma has been identified as a factor that influences medical student attitudes towards psychiatry (Totic et al., 2012, Roberts and Bandstra, 2012) and makes them less likely to consider psychiatry as a career (Lyons, 2013). Good quality education has been found to reduce stigma and the Cambridge Medicine course includes sessions that address stigma directly (Zalar et al., 2007). While it is disappointing that self-reported interest in psychiatry as a career does not significantly change in our sample, it is positive that it does not reduce as suggested in similar studies (Warnke et al., 2018). In other previous research, McParland et al reported a lower initial ATP score, and found that students with already positive attitudes towards psychiatry did not change after placement, with no impact on career choice (McParland et al., 2003). Potentially due to improvements in mental health stigma over time, our baseline ATP scores are higher, resulting in less room for change comparatively. It is possible that career aspirations at medical school don't reflect actual career choice, and a longitudinal study assessing future career choices of medical students is warranted. It is very likely that improved attitudes towards psychiatry do in fact affect future career choice, as the success of the "Choose Psychiatry" campaign suggests. This might not be 
reflected in this study as it may take longer for the improved attitudes to impact on career choice through additional means, such as peer pressure or acceptance of choice over time.

We also found that higher agreeableness personality scores significantly predicted both self-rated likelihood of taking up psychiatry, and more positive attitudes towards psychiatry. We did not find the predicted association between openness and psychiatry. However, our findings that agreeableness associates with psychiatry are compatible with previous evidence that agreeableness is beneficial for doctors' collaboration and communication skills (Lievens et al., 2002), two skills that are at the core of psychiatry. It is interesting that we have not replicated previous results, showing that students with higher levels of openness were more likely to select psychiatry as a career (Malhi et al., 2011, Mullola et al., 2018). This may be due to cultural differences, as the other studies were from outside of the UK; although may be a type 2 error due to relatively small sample size.

This study has important limitations. Crucially, assessments were cross-sectional, meaning differences between year 4 and 6 may have been due to cohort effects rather than change within cohorts. Longitudinal studies are needed to look at change in attitudes within individual students, including validating self-reported future career choices. Furthermore, we recruited around $17 \%$ of the students in each year, and it is likely that this introduced some degree of selection bias in terms of personalities and attitudes towards psychiatry. In addition, we compared students before and after exposure to psychiatry placements - in their $4^{\text {th }}$ and $6^{\text {th }}$ years - however these were different students, so differences might also be due to cohort effects. Moreover, students were recruited from two consecutive academic years, potentially introducing stratification; however, there were no differences in age, sex, sex by year, year of study, specialism preference, ATP30 score or likelihood to choose psychiatry between the 2018 and 2019 cohorts, suggesting that the two cohorts were very similar and comparable. It is important to say that comparing attitudes towards psychiatry and self- 
reported likelihood of choosing psychiatry between the $4^{\text {th }}$ and $6^{\text {th }}$ year might also include variance due to factors different from exposure to placements, such as ongoing campaigns or other engagement events (such as Choose Psychiatry). A final limitation is about sample size: we did detect an association between exposure to psychiatry placements and improved ATPs (primary aim), however part of the other negative findings might be due to a type 2 statistical error, as the analyses were not powered, e.g., to detect change in likelihood to take up psychiatry as a career.

In conclusion, in a sample of medical students from Cambridge University we found that attitudes towards psychiatry may have improved following exposure to psychiatry teaching and placements. Furthermore, students with higher agreeableness personality scores had more positive attitudes towards psychiatry.

A longitudinal study across a wide set of medical settings would be beneficial to confirm our findings; a future longitudinal study should also address whether exposure to psychiatry during the early parts of postgraduate medical training, such as the UK Foundation Programme, has similar beneficial effect for improving views about psychiatry. A longitudinal study could also confirm if actual recruitment figures into postgraduate psychiatry training improve following increased exposure of medical students to psychiatry placements and wider training.

\section{Author Contributions}

All authors contributed to the design of the study, set up of the questionnaires, and data collection. EFO performed the statistical analyses. All authors contributed to the drafting of the manuscript. 


\section{Acknowledgements}

This work was funded by a National Institute of Health Research (NIHR) Academic Clinical

Fellowship to Dr Osimo.

Dr Wilkinson contributed to prize draws for participants.

The study team would like to thank Barry Widmer for the support in setting up RedCap, the platform used for electronically administering the questionnaires.

The funding bodies had no role in design and conduct of the study; collection, management, analysis and interpretation of the data; preparation, review or approval of the manuscript; or the decision to submit the manuscript for publication.

\section{Financial disclosures}

Dr Wilkinson is psychiatry placement lead until December 2020 and Clinical Dean from January 2021 at Cambridge University. All authors are psychiatrists. The authors have no other conflict of interests or financial disclosures to declare. 


\section{References}

Burra, P., Kalin, R., Leichner, P., Waldron, J., Handforth, J., Jarrett, F. and Amara, I. (1982), "The ATP 30-a scale for measuring medical students' attitudes to psychiatry", Medical education, Vol. 16 No. 1, pp. 31-38.

Goldberg, L. R. (1990), "An alternative" description of personality": the big-five factor structure", Journal of personality and social psychology, Vol. 59 No. 6, p. 1216.

Harris, P. A., Taylor, R., Thielke, R., Payne, J., Gonzalez, N. and Conde, J. G. (2009), "Research electronic data capture (REDCap)-a metadata-driven methodology and workflow process for providing translational research informatics support", Journal of biomedical informatics, Vol. 42 No. 2, pp. 377-381.

John, O. P. and Srivastava, S. (1999), "The Big Five trait taxonomy: History, measurement, and theoretical perspectives", Handbook of personality: Theory and research, Vol. 2 No. 1999, pp. 102-138.

Kuhnigk, O., Strebel, B., Schilauske, J. and Jueptner, M. (2007), "Attitudes of medical students towards psychiatry", Advances in health sciences education, Vol. 12 No. 1, pp. 87-101.

Lievens, F., Coetsier, P., De Fruyt, F. and De Maeseneer, J. (2002), "Medical students' personality characteristics and academic performance: A five-factor model perspective", Medical education, Vol. 36 No. 11, pp. 1050-1056.

Lyons, Z. (2013), "Attitudes of medical students toward psychiatry and psychiatry as a career: a systematic review", Academic Psychiatry, Vol. 37 No. 3, pp. 150-157.

Malhi, G. S., Coulston, C. M., Parker, G. B., Cashman, E., Walter, G., Lampe, L. A. and Vollmer-Conna, U. (2011), "Who picks psychiatry? Perceptions, preferences and personality of medical students", Australian \& New Zealand Journal of Psychiatry, Vol. 45 No. 10, pp. 861-870.

McCaulley, M. H. (1977), The Myers Longitudinal Medical Study. Monograph II. Final Report, ERIC.

McCrae, R. R. and Costa Jr, P. T. (2008), "The five-factor theory of personality".

McCrae, R. R. and John, O. P. (1992), "An introduction to the five-factor model and its applications", Journal of personality, Vol. 60 No. 2, pp. 175-215.

McParland, M., Noble, L. M., Livingston, G. and McManus, C. (2003), "The effect of a psychiatric attachment on students' attitudes to and intention to pursue psychiatry as a career", Medical education, Vol. 37 No. 5, pp. 447-454.

Mukherjee, K., Maier, M. and Wessely, S. (2013), "UK crisis in recruitment into psychiatric training", The Psychiatrist, Vol. 37 No. 6, pp. 210-214.

Mullola, S., Hakulinen, C., Presseau, J., de Porras, D. G. R., Jokela, M., Hintsa, T. and Elovainio, M. (2018), "Personality traits and career choices among physicians in Finland: employment sector, clinical patient contact, specialty and change of specialty", BMC medical education, Vol. 18 No. 1, p. 52.

Niedermier, J. A., Bornstein, R. and Brandemihl, A. (2006), "The junior medical student psychiatry clerkship: curriculum, attitudes, and test performance", Academic Psychiatry, Vol. 30 No. 2, pp. 136-143.

R Core Team (2020), "R: A language and environment for statistical computing [Software]", Vienna, Austria, R Foundation for Statistical Computing.

Roberts, L. W. and Bandstra, B. S. (2012), "Addressing stigma to strengthen psychiatric education", Citeseer. 
Royal College of Psychiatrists (2019a), "Invitation to tender. Understanding career choices in Psychiatry".

Royal College of Psychiatrists (2019b), "Number of junior doctors choosing psychiatry at all time high".

Royal College of Psychiatrists (2019c), "Pre-report summary of the 2019 census".

Stilwell, N. A., Wallick, M. M., Thal, S. E. and Burleson, J. A. (2000), "Myers-Briggs type and medical specialty choice: a new look at an old question", Teaching and Learning in Medicine, Vol. 12 No. 1, pp. 14-20.

Strebel, B., Obladen, M., Lehmann, E. and Gaebel, W. (2000), "Attitude of medical students to psychiatry. A study with the German translated, expanded version of the ATP-30", Der Nervenarzt, Vol. 71 No. 3, pp. 205-212.

Totic, S., Stojiljković, D., Pavlovic, Z., Zaric, N., Zarkovic, B., Malic, L., Mihaljevic, M., Jašović-Gašić, M. and Marić, N. P. (2012), "Stigmatization of 'psychiatric label'by medical and non-medical students", International Journal of Social Psychiatry, Vol. 58 No. 5, pp. 455-462.

Urbanek, S. and Horner, J. (2005), "Cairo: R graphics device using cairo graphics library for creating high-quality bitmap (PNG, JPEG, TIFF), vector (PDF, SVG, PostScript) and display (X11 and Win32) output", R package version 1.5-9 ed.

Warnke, I., Gamma, A., Buadze, M., Schleifer, R., Canela, C., Strebel, B., Tényi, T., Rössler, W., Rüsch, N. and Liebrenz, M. (2018), "Predicting Medical Students' Current Attitudes Toward Psychiatry, Interest in Psychiatry, and Estimated Likelihood of Working in Psychiatry: A Cross-Sectional Study in Four European Countries", Frontiers in psychiatry, Vol. 9, p. 49.

Wickham, H. (2009), ggplot2: Elegant Graphics for Data Analysis, Springer-Verlag, New York.

Zalar, B., Strbad, M. and Švab, V. (2007), "Psychiatric education: does it affect stigma?", Academic Psychiatry, Vol. 31 No. 3, pp. 245-246.

Zwerenz, R., Barthel, Y., Leuzinger-Bohleber, M., Gieler, U., Rudolf, G., Schwarz, R., Vogel, J. and Beutel, M. E. (2007), "Attitudes of medical students towards psychotherapeutic treatment and training", Zeitschrift fur Psychosomatische Medizin und Psychotherapie, Vol. 53 No. 3, pp. 258-272. 